\title{
The effect of feeding system on slaughter-carcass characteristics, meat quality, and fatty acid composition of lambs
}

\author{
Serhat Karaca ${ }^{1}$, Ayhan Yılmaz ${ }^{2}$, Asskın Kor ${ }^{1}$, Mehmet Bingöl ${ }^{1}$, İsa Cavidoğlu ${ }^{3}$, and Gazel Ser ${ }^{1}$ \\ ${ }^{1}$ Department of Animal Sciences, Faculty of Agriculture, Yuzuncu Y1l University, 65080 Van, Turkey \\ ${ }^{2}$ Department of Animal Sciences, Faculty of Agriculture, Siirt University, 56100 Siirt, Turkey \\ ${ }^{3}$ Department of Food Engineering, Faculty of Engineering and Architecture, \\ Yuzuncu Y1l University, 65080 Van, Turkey
}

Correspondence to: Serhat Karaca (serhatkaraca@gmail.com, skaraca@yyu.edu.tr)

Received: 29 October 2015 - Revised: 15 January 2016 - Accepted: 19 February 2016 - Published: 1 March 2016

\begin{abstract}
In this study, we aimed to determine the slaughter-carcass characteristics, meat quality, and fatty acid composition in lambs raised under intensive and extensive conditions. The animal material consisted of 30 Norduz male lambs, with an average age of 171 days. The lambs were divided into two groups: concentrate-fed lambs (CO) and pasture-fed lambs (PS). The results showed that the CO lambs had heavier carcasses $(p<0.001)$, a higher dressing percentage $(p<0.001)$, and higher intramuscular fat $(p<0.01)$ than the PS lambs. It was determined that the longissimus thoracis muscle of the $\mathrm{CO}$ lambs had a lower ultimate $\mathrm{pH}$ and higher $L^{*}$ and water-holding capacity than the PS lambs. In this study, intramuscular fat (longissimus thoracis, semimembranosus, triceps brachii), subcutaneous and tail fat samples were used to evaluate the effect of feeding system on fatty acid composition. The polyunsaturated fatty acid to saturated fatty acid ratio (PUFA / SFA) of intramuscular fat was found to be significantly higher in the CO group than in the PS lambs, while similar subcutaneous and tail fat results were found in both groups. Moreover, the PS lambs had a lower n6 / n3 ratio and higher percentage of omega-3 than the CO lambs in all tissues studied $(p<0.05)$. Overall, the CO lambs have heavier and fattier carcasses with better meat quality traits than the PS lambs. However, the effects of feeding system have varying results based on the fatty acid composition of different types of fat deposits.
\end{abstract}

\section{Introduction}

Carcass and meat quality are dependent on many factors and one of the most important environmental factors amongst these is the feeding system. Previous studies that predominantly compared pasture vs. grain feeding indicated that growth performance and carcass characteristics (Carrasco et al., 2009b; Ripoll et al., 2008), meat quality traits, such as color (Priolo et al., 2001; Ripoll et al., 2008), water-holding capacity (WHC) (Santos-Silva et al., 2002b), sensory characteristics (Duckett et al., 2013; Fisher et al., 2000), fatty acid (FA) profile (Karaca and Kor, 2015; Nuernberg et al., 2008), and oxidative stability (Popova, 2007), can also be affected by feeding systems. In general, pasture-fed lambs have leaner carcasses, lower dressing percentage, and more beneficial FAs, whereas concentrate-fed lambs have higher growth rates, better carcass conformation, a less problematic ultimate $\mathrm{pH}$, and a higher $\mathrm{n} 6 / \mathrm{n} 3$ ratio (Wood et al., 2008; Zervas and Tsiplakou, 2011).

Although ruminal biohydrogenation is the main factor in modifying dietary unsaturated fatty acids, the n-3 FA content differences between pasture and concentrate, in particular, make the feeding system important. The quantity and structure of FA intake modulates the metabolism, physiology, and immune response in humans, and, therefore, changes in the FA intake affect the risk of developing some chronic diseases, particularly cardiovascular diseases. Thus, increasing n-3 FA content is the common goal of the strategies to improve the lipid profile of meat (Bessa et al., 2015). 
Pastures plays a very important role in small ruminant breeding and in extensive animal feeding, which is common practice in Turkey, where supplementation of lambs with commercial concentrate is limited. Norduz is a fat-tailed sheep breed native to the Eastern Anatolian province of Van, and meat quality and lipid contents have not been studied to date. The aim of the present study was to determine the effect of the feeding system on slaughter-carcass characteristics, meat quality, and FA profile of different types of fat deposits in Norduz lambs.

\section{Materials and methods}

\subsection{Animals, diets, and experimental design}

The study group consisted of 30, single-born, male Norduz lambs. The 30 lambs (age: 160-185 days; mean: 171 days; live weight: $35.01 \pm 0.338 \mathrm{~kg}$ ) were assigned to one of the two dietary regimes: 15 lambs grazed on pasture (PS) and 15 lambs were fed with concentrate ration in stall (CO). The grazing pasture, populated with multiple species of native plants, was located at $38^{\circ} 18^{\prime} \mathrm{N}$ and $42^{\circ} 49^{\prime} \mathrm{E}$ and $2460 \mathrm{~m}$ above sea level. The pasture has also been documented by Beyis (2009), who stated that $14.3 \%$ Poaceae (grasses) and $13.4 \%$ Fabaceae (legume) taxa contributed to the floristic composition, with $72.3 \%$ taxa from other plant families, from which a hay harvest yielded $955 \mathrm{~kg} \mathrm{ha}^{-1}$. For the nutrient composition of the pasture, given in Table 1, the values determined by Karaca (2010) in the following year for the same pasture were used. Each lamb on the concentrate diet was fed with $200 \mathrm{~g}$ of alfalfa hay and ad libitum concentrate (barley $72.5 \%$, cotton seed pulp $24.0 \%$, calcium carbonate $\left(\mathrm{CaCO}_{3}\right) 2.4 \%$, salt $(\mathrm{NaCl}) 0.5 \%$, vitamin supplement $0.5 \%$, and mineral supplement $0.1 \%$ ). The chemical compositions of the diets of the lambs are given in Table 1.

\subsection{Sampling procedures and instrumental analyses}

All lambs were slaughtered after $12 \mathrm{~h}$ of fasting at the end of the fattening period of 84 days. After slaughter, the carcasses were stored at $4{ }^{\circ} \mathrm{C}$ for $24 \mathrm{~h}$. The jointing of carcasses was based on the method given by Colomer-Rocher et al. (1987). The longissimus thoracis (LT) muscle (6th-13th ribs) was removed from the left side of the carcass at $24 \mathrm{~h}$ postmortem and used for color, water-holding capacity, proximate and FA analyses. In addition to this, the semimembranosus (SM) and triceps brachii (TB) muscles, tail fat (TF), and subcutaneous (SC) fat samples were removed from each carcass for FA profile determination.

Carcass $\mathrm{pH}$ was measured at 45 min post-slaughter $\left(\mathrm{pH}_{45}\right)$ and at $24 \mathrm{~h}$ post-slaughter $\left(\mathrm{pH}_{24}\right)$ using a digital $\mathrm{pH}$ meter (Hanna HI 99163N, Hanna instruments, Romania) equipped with a penetrating electrode and thermometer. The $\mathrm{pH}$ was directly measured on the LT muscle between the 12th and 13 th thoracic vertebrae. In order to determine meat color,
Table 1. Chemical composition of concentrate and pasture hay.

\begin{tabular}{lrr}
\hline Composition & Experimental diet & Pasture hay \\
\hline Crude protein (\% DM) & 14.71 & 10.44 \\
Ether extract (\% DM) & 2.30 & 1.87 \\
Ash (\% DM) & 9.42 & 7.26 \\
ADF (\% DM) & 20.24 & 29.09 \\
NDF (\% DM) & 38.56 & 50.47 \\
Crude fiber & 14.18 & 32.27 \\
Metabolizable energy & 10.94 & 9.93 \\
(MJ kg DM ${ }^{-1}$ ) & & \\
\hline Fatty acid composition (fatty acids, \%) & & \\
\hline C10:0 & & \\
C12:0 & 0.02 & 0.04 \\
C14:0 & 0.13 & 0.65 \\
C14:1 & 0.78 & 2.01 \\
C15:0 & 0.09 & 0.30 \\
C15:1 & 0.04 & 0.25 \\
C16:0 & 0.40 & 0.23 \\
C16:1 & 21.58 & 23.09 \\
C17:0 & 0.37 & 0.88 \\
C18:0 & 0.14 & 0.77 \\
C18:1 & 2.75 & 3.91 \\
C18:2 & 18.20 & 12.29 \\
C18:3 & 46.93 & 15.73 \\
C20:0 & 6.53 & 32.71 \\
C20:1 & 0.11 & 0.26 \\
Others & 0.58 & nd \\
\hline & 1.35 & 6.88 \\
\hline
\end{tabular}

* by Karaca (2010); nd: not detected; DM: dry matter.

each sample had five measurements, from the fat-free areas, using a Lovibond RT-300 portable spectrophotometer (The Tintometer Limited, UK) (CIELAB-Illuminant $\mathrm{D}_{65} / 10^{\circ}$ ) at $24 \mathrm{~h}$ post-slaughter. The measurements were performed on a freshly cut surface of $2.5 \mathrm{~cm}$ thick LT (12th-13th ribs) after allowing the muscle surface to bloom in the chiller for 45 min. Water-holding capacity (WHC) was determined according to Wierbicki and Deatherage (1958), where a $0.5 \mathrm{~g}$ sample of muscle tissue was placed on filter paper and pressed at $500 \mathrm{psi} \mathrm{min}^{-1}$ between two plexiglass plates. The results were expressed as the percentage of free water.

Longissimus muscle samples were vacuum-packed and frozen to $-18^{\circ} \mathrm{C}$ for use in chemical analysis. The samples were then thawed overnight, preceding the start of the analysis, and minced and homogenized. The nutrient content was analyzed according to AOAC (2000) by homogenizing the samples and measuring dry matter, ash, fat, and protein content (moisture: 950.46; ash: 920.153; fat: 960.39 (determined using ether extraction); protein: 928.08 (determined using the Kjeldahl method)). Neutral detergent fiber (NDF) and acid detergent fiber (ADF) contents of feed samples were determined according to Van Soest and Robertson (1979).

Fatty acid analysis was performed on samples that had been stored at $-18^{\circ} \mathrm{C}$ for 1 month and then allowed to 
thaw overnight at $4{ }^{\circ} \mathrm{C}$. Fat samples that were used included SC (from above the 6th-12th chop) and TF, and intramuscular fat taken from the LT, SM, and TB muscle samples. Muscle $(25 \mathrm{~g})$ or fat $(2 \mathrm{~g})$ were homogenized with chloroform-methanol $(2: 1, v / v)$, and total lipids were extracted according to the procedure described by Folch et al. (1957); methylation was performed as described previously by Basturk et al. (2007). FA composition was determined by gas chromatography (Agilent $6890 \mathrm{~N}$, Agilent Technology, USA) equipped with a flame ionization detector and a polar capillary column (DB-23, Agilent Technology, USA; $60 \mathrm{~m} \times 0.25 \mathrm{~mm}$ I.D., $0.25 \mu \mathrm{m})$. Helium was used as the carrier gas $\left(1.5 \mathrm{~mL} \mathrm{~min}^{-1}\right)$. The oven temperature was programmed at $120^{\circ} \mathrm{C}$ for $5 \mathrm{~min}$, increased to $240^{\circ} \mathrm{C}$ at a rate of $15^{\circ} \mathrm{C} \mathrm{min}^{-1}$ and held at $240^{\circ} \mathrm{C}$ for $20 \mathrm{~min}$. FA methyl esters were identified by matching their retention times with those of their relative standards (Supelco 37 component FAME Mix, Sigma-Aldrich Co., USA). Moreover, the fatty acid composition of feed samples was determined according to the official EEC (1991) method (2568/91).

\subsection{Indices and sums calculations}

The saturated fatty acids (SFAs), monounsaturated fatty acids (MUFAs) and polyunsaturated fatty acids (PUFAs) were calculated with the following Eqs. (1-3):

$$
\begin{aligned}
\text { SFA }= & \mathrm{C} 10: 0+\mathrm{C} 12: 0+\mathrm{C} 14: 0+\mathrm{C} 15: 0+\mathrm{C} 16: 0 \\
& +\mathrm{C} 17: 0+\mathrm{C} 18: 0+\mathrm{C} 20: 0, \\
\text { MUFA }= & \mathrm{C} 14: 1+\mathrm{C} 15: 1+\mathrm{C} 16: 1+\mathrm{C} 17: 1 \\
& +\mathrm{C} 18: 1 \mathrm{n}-9+\mathrm{C} 20: 1,
\end{aligned}
$$

PUFA $=\mathrm{C} 18: 2 \mathrm{n}-6+\mathrm{C} 18: 3 \mathrm{n}-6(\gamma)+\mathrm{C} 18: 3 \mathrm{n}-3(\alpha)$.

The desirable fatty acids (DFAs) were calculating according to Huerta-Leidenz et al. (1991) with the following Eq. (4):

DFA $=$ Total unsaturated fatty acids (TUFA) + C18:0

Activities of desaturase activity indices were calculated according to Juárez et al. (2008) with the following Eqs. (5) and (6):

$$
\begin{aligned}
& \Delta 9 \mathrm{DS}(\mathrm{C} 16)=100 \times[\mathrm{C} 16: 1 /(\mathrm{C} 16: 0+\mathrm{C} 16: 1)], \\
& \Delta 9 \mathrm{DS}(\mathrm{C} 18)=100 \times[\mathrm{C} 18: 1 /(\mathrm{C} 18: 0+\mathrm{C} 18: 1)] .
\end{aligned}
$$

\subsection{Statistical analyses}

One-way analysis of variance was performed using the Minitab 13.0 software program. Except for FAs, data were analyzed according to the following Eq. (7):

$y_{i j}=\mu+a_{i}+e_{i j}$.
The FA composition of different anatomical regions, in both PS and CO groups, was examined using the Eq. (8):

$y_{i j k}=\mu+a_{i}+b_{j}+(a b)_{i j}+e_{i j k}$,

where $y_{i j k}$ is the value of the examined characteristic for the $k$ th animal in the $j$ th anatomical region from the $i$ th feeding system; $\mu$ is the overall mean; $a_{i}$ is the fixed effect of feeding system $\left(a_{i}\right.$ : concentrate or pasture); $b_{j}$ is the fixed effect of anatomical region ( $j: \mathrm{SC}, \mathrm{TF}, \mathrm{LT}, \mathrm{SM}$, and $\mathrm{TB}) ;(a b)_{i j}$ is the interaction of the effects; and $e_{i j k}$ is the random error. The principal component analysis was performed using the multivariate subsection of Minitab 13.0.

\section{Results and discussion}

\subsection{Slaughter-carcass traits and meat quality}

The results of slaughter traits for lambs raised under different feeding systems are given in Table 2. It was determined that the CO group had a higher slaughter and carcass weight than the PS group at the end of the fattening period. The dressing percentages were found to be lower in the PS lambs rather than the CO lambs. It has been frequently reported (Karaca and Kor, 2015; Priolo et al., 2002) that pasture-fed lambs have lower dressing percentages than concentrate-fed lambs, and this is thought to be related to the differences in the gastrointestinal content and fattening level of the feeding groups. Papi et al. (2011) reported that lambs fed low-energy and high-fiber diets had a higher digestive system content than those fed high-energy diets. The CO lambs had significantly higher omental-mesenteric fat (226.3 vs. $118.49 \mathrm{~g} ; p<0.05)$ and kidney-knob and channel fat ( 175.0 vs. $114.4 \mathrm{~g} ; p<0.05$ ) than the PS lambs (data not shown in the table), whereas the percentages of fat recorded at the slaughter and cold carcass weights were found to be similar between the two groups (Table 2). The weights of the non-carcass parts, such as feet, which correlate with poor body growth, were greater in the PS lambs than the CO lambs and are consistent with those reported by Moron-Fuenmayor and Clavero (1999).

Meat quality traits of $\mathrm{CO}$ and PS lambs are presented in Table 3. Although $\mathrm{pH}_{45}$ min results were similar between groups, PS lambs had significantly higher $\mathrm{pH}_{24} \mathrm{~h}$ than $\mathrm{CO}$ lambs. The ultimate high $\mathrm{pH}$ in PS lambs can be related to higher muscle activity and a low-energy diet in these lambs compared to CO lambs. Some studies have also shown that increases in metabolic energy of the diet result in parallel increases in the muscle glycogen content (Immonen et al., 2000). Further results (Duckett et al., 2013; Karaca and Kor, 2015) also support the abovementioned findings, and the ultimate $\mathrm{pH}$ was higher in the lambs fed on pasture than lambs fed with a high-energy diet. However, it was reported by different researchers that the different feeding systems had limited effects, particularly on $\mathrm{pH}$, as well as on the WHC 
Table 2. Means for slaughter and carcass traits of concentrate (CO) and pasture lambs (PS).

\begin{tabular}{lrrr}
\hline & $\mathrm{CO}(n=15)$ & PS $(n=13)$ & $p$ \\
\hline Slaughter weight $(\mathrm{kg})$ & $54.82 \pm 0.438$ & $40.70 \pm 0.444$ & $<0.001$ \\
Hot carcass $(\mathrm{kg})$ & $27.18 \pm 0.318$ & $17.91 \pm 0.447$ & $<0.001$ \\
Dressing percentage $(\%)$ & $49.57 \pm 0.363$ & $43.97 \pm 0.779$ & $<0.001$ \\
\hline Proportions in slaughter weight $(\%)$ & & \\
\hline Head & $5.61 \pm 0.099$ & $5.87 \pm 0.193$ & 0.197 \\
Four feet & $2.03 \pm 0.035$ & $2.34 \pm 0.024$ & $<0.001$ \\
Skin & $12.62 \pm 0.258$ & $12.15 \pm 0.322$ & 0.259 \\
Omental-mesenteric fat & $0.38 \pm 0.077$ & $0.29 \pm 0.032$ & 0.336 \\
Heart-lung-liver & $4.02 \pm 0.058$ & $4.07 \pm 0.079$ & 0.576 \\
Spleen & $0.24 \pm 0.016$ & $0.28 \pm 0.040$ & 0.324 \\
Cold carcass (kg) & $26.68 \pm 0.304$ & $17.55 \pm 0.434$ & $<0.001$ \\
Chilling loss (\%) & $1.85 \pm 0.217$ & $2.00 \pm 0.216$ & 0.638 \\
\hline Proportions in cold carcass $(\%)$ & & \\
\hline Testes & $1.56 \pm 0.103$ & $1.57 \pm 0.158$ & 0.971 \\
Kidneys & $0.52 \pm 0.016$ & $0.64 \pm 0.024$ & $<0.001$ \\
Kidney-knob channel fat & $0.65 \pm 0.069$ & $0.65 \pm 0.071$ & 0.985 \\
Tail fat & $16.04 \pm 0.941$ & $13.15 \pm 0.728$ & 0.037 \\
Left half carcass (kg) & $11.12 \pm 0.183$ & $7.86 \pm 0.110$ & $<0.001$ \\
\hline Proportions in left half carcass $(\%)$ & & \\
\hline Foreleg & $17.72 \pm 0.217$ & $19.35 \pm 0.329$ & $<0.001$ \\
Hind leg & $33.11 \pm 0.549$ & $34.41 \pm 0.401$ & 0.098 \\
Neck & $8.60 \pm 0.374$ & $8.13 \pm 0.479$ & 0.448 \\
Flank & $13.29 \pm 0.443$ & $12.67 \pm 0.422$ & 0.347 \\
Back loin & $20.88 \pm 0.735$ & $19.62 \pm 0.601$ & 0.233 \\
Shoulder & $5.98 \pm 0.263$ & $5.79 \pm 0.280$ & 0.635 \\
\hline Commercial categories $(\%)$ & & & \\
\hline First quality & $59.99 \pm 0.693$ & $59.83 \pm 0.849$ & 0.887 \\
Second quality & $17.72 \pm 0.217$ & $19.35 \pm 0.329$ & $<0.001$ \\
Third quality & $21.90 \pm 0.554$ & $20.82 \pm 0.679$ & 0.228 \\
\hline & & & \\
\hline
\end{tabular}

First quality: hind leg, back loin and shoulder; second quality: foreleg; third quality: neck and flank.

and tenderness of the meat (Diaz et al., 2002; Sanudo et al., 2007).

The ultimate $\mathrm{pH}$ of meat has a determining role in the meat color, and high ultimate $\mathrm{pH}$ results in a darker color compared to a lower $\mathrm{pH}$ (Sanudo et al., 2007). Comparable to these reports, PS lambs in our study, with a high ultimate $\mathrm{pH}$, had lower luminosity $\left(L^{*}\right)(p<0.001)$ compared to $\mathrm{CO}$ lambs. Similar to our findings, research has shown that the meat color in PS lambs is darker than that in CO lambs (Diaz et al., 2002; Karaca and Kor, 2015; Priolo et al., 2002). In addition, Minchin et al. (2009) reported that the brighter appearance of meat from cows fed with high-energy diets can be due to the changes caused in reflectance values by increased fat deposition. However, Priolo et al. (2001) reported that the meat color was darker in pasture-fed lambs, even in conditions where fat deposition was high, when compared to concentrate-fed lambs.

Another important consideration in the pasture-fed lambs is the redness of meat or the $a^{*}$ value. It was reported that the
Table 3. Means for meat quality traits of concentrate $(\mathrm{CO})$ and pasture lambs (PS).

\begin{tabular}{lrrr}
\hline & $\mathrm{CO}(n=15)$ & PS $(n=13)$ & $p$ \\
\hline $\mathrm{pH}_{45 \mathrm{~min}}$ & $6.42 \pm 0.044$ & $6.44 \pm 0.047$ & 0.778 \\
$\mathrm{pH}_{24 \mathrm{~h}}$ & $5.94 \pm 0.061$ & $6.15 \pm 0.020$ & 0.002 \\
\hline$L^{*}$ & $38.07 \pm 0.315$ & $34.53 \pm 0.685$ & $<0.001$ \\
$a^{*}$ & $21.53 \pm 0.365$ & $20.36 \pm 0.653$ & 0.107 \\
$b^{*}$ & $6.71 \pm 0.320$ & $5.33 \pm 0.390$ & 0.012 \\
$C^{*}$ & $22.57 \pm 0.415$ & $21.06 \pm 0.717$ & 0.063 \\
$h^{\circ}$ & $17.24 \pm 0.646$ & $14.56 \pm 0.680$ & 0.011 \\
WHC (percentage of free water) & $34.91 \pm 1.616$ & $37.39 \pm 0.962$ & 0.250 \\
\hline Nutrient matter $(\%)$ & & & \\
\hline Moisture & & & \\
Protein & & & \\
$\quad(\%$ DM) & $74.98 \pm 0.219$ & $78.54 \pm 0.271$ & $<0.001$ \\
Ether extract & $20.97 \pm 0.274$ & $18.92 \pm 0.308$ & $<0.001$ \\
$\quad(\%$ DM) & $83.86 \pm 0.961$ & $88.18 \pm 0.745$ & 0.004 \\
Ash & $3.16 \pm 0.324$ & $1.68 \pm 0.208$ & 0.002 \\
$\quad(\%$ DM) & $12.58 \pm 1.238$ & $7.80 \pm 0.949$ & 0.010 \\
\hline DM: dry matter; $L^{*}:$ lightness, $a^{*}:$ redness, $b^{*}:$ yellowness, $C^{*}:$ chroma $h^{\circ}:$ hue angle &
\end{tabular}

DM: dry matter; $L^{*}$ : lightness, $a^{*}$ : redness, $b^{*}$ : yellowness, $C^{*}$ : chroma, $h^{\circ}$ : hue angle

$a^{*}$ value was higher in pasture-fed lambs than in concentratefed lambs (Carrasco et al., 2009a; Ripoll et al., 2008). The high $a^{*}$ value is associated with raised pigmentation depending on increased muscle activity and live weight of the lambs (Ripoll et al., 2008; Sanudo et al., 2007; Carrasco et al., 2009a). In our study, no significant difference with respect to the $a^{*}$ value could be found between the CO and PS lambs. Thus, it can be suggested that increases in the $a^{*}$ values due to high slaughter weight of $\mathrm{CO}$ lambs may lead to similar results in these groups. In addition to this, meat yellowness $\left(b^{*}\right)$ and saturation $\left(h^{\circ}\right)$ values were significantly higher in CO lambs than in PS lambs $(p<0.05)$ (Table 3$)$. The high ultimate $\mathrm{pH}$ of PS lambs had a negative effect on meat color parameters and plays an important role in the variance between $b^{*}$ and $h^{\circ}$ values.

It was determined that the percentage of free water was lower and WHC was better in the CO lambs than in the PS lambs (Table 3). Santos-Silva et al. (2002b) reported similar results. However, Diaz et al. (2002) found no difference in WHC in concentrate- and pasture-fed lambs. It is also known that in meats with a higher ultimate $\mathrm{pH}$, the WHC increases (Sanudo et al., 2007). However, in our study, the PS lambs had a higher ultimate $\mathrm{pH}$ than the CO lambs, which had a lower WHC. It seems that the higher fat deposition recorded in the $\mathrm{CO}$ group affected the results of WHC.

The production system was also found to have an important effect on the nutritional content of the meat in the present study (Table 3). The moisture content in meat was found to be higher in PS lambs than in CO lambs $(p<0.001)$, while the protein and fat content was higher in CO lambs. It should be noted that the dry matter content also varied between the groups due to differences in the moisture content of the nutrients. When these results were evaluated on the basis of dry matter (DM \%), protein and ash were found to be higher in 
Table 4. Least square means for percentage of fatty acids in depot fat (subcutaneous (SC) and tail fat (TF)) of concentrate (CO) and pasture lambs (PS).

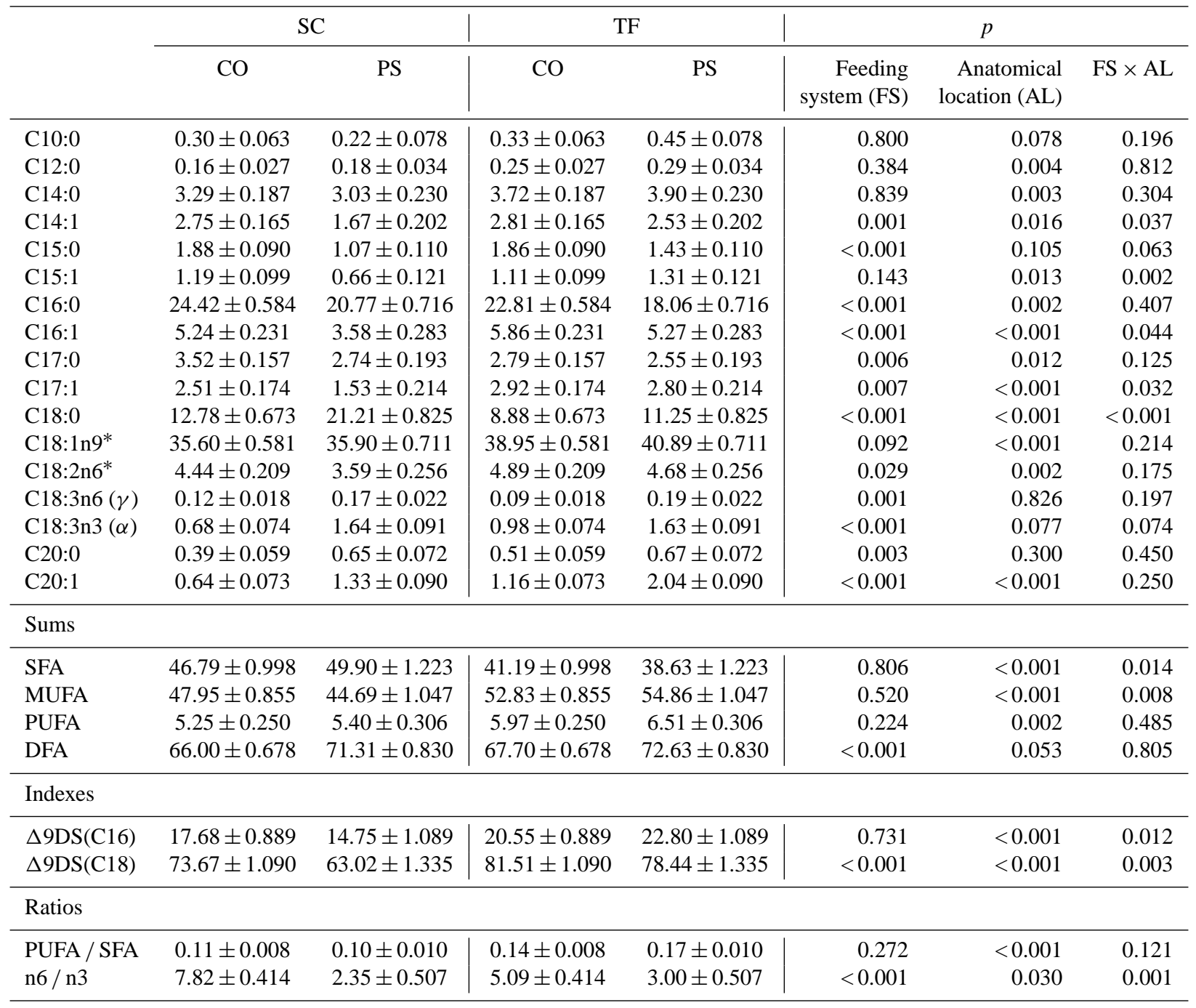

* Sum of the cis and trans isomers. SFA: saturated fatty acids; MUFA: monounsaturated fatty acids; PUFA: polyunsaturated fatty acids; $\Delta 9 \mathrm{DS}(18): \Delta 9$-desaturase (C18) index; $\Delta$ 9DS(16): $\Delta$ 9-desaturase (C16) index.

the PS lambs. In similar studies, it was determined that the moisture content was higher in the pasture-fed lambs than in the concentrate-fed lambs, while the fat content was lower (Karaca and Kor, 2015; Rowe et al., 1999).

\subsection{FA composition of adipose tissue}

In ruminants, most dietary unsaturated FAs are hydrolyzed and then form saturated FAs, and this process varies significantly depending on the biohydrogenation activity (Wood et al., 2008; Zervas and Tsiplakou, 2011). Comparing the effects of the feeding system in terms of the percentages of C16:0 and C18:0 FA in depot fats, it can be observed that the percentage of $\mathrm{C} 16: 0$ was higher in the $\mathrm{CO}$ lambs, whereas the percentage of C18:0 was higher in the PS lambs (Table 4). In terms of the intramuscular fat in CO and PS lambs, the per- centage of C18:0 was found to be higher in the PS lambs (Table 5). Similar results were also obtained in some previous studies (Diaz et al., 2002; Guler et al., 2011; Rowe et al., 1999). The amount of C12:0, C14:0, and C16:0 found in meat is important due to the hypercholesterolemic effects, which may increase the risk of atherosclerosis and thus have adverse effects on human health (Zock et al., 1994). The amount of C18:0, which is one of the primary FAs in ruminant meats, depends on the biohydrogenation of unsaturated C18 FAs. The biohydrogenation activity of polyionic FAs decreased due to the concentrate diet reducing rumen $\mathrm{pH}$ levels and the time spent by the concentrate in the rumen when compared to that of forage (Jenkins et al., 2008; Wood et al., 2008; Diaz et al., 2002). However, it was reported that there were similarities in the percentages of C16:0 and C18:0 in 
Table 5. Least square means for percentage of fatty acids in intramuscular fat (longissimus thoracis, LT; semimembranosus, SM; triceps brachii, TB) of concentrate (CO) and pasture lambs (PS).

\begin{tabular}{|c|c|c|c|c|c|c|c|c|c|}
\hline & \multicolumn{2}{|c|}{ LT } & \multicolumn{2}{|c|}{ SM } & \multicolumn{2}{|c|}{ TB } & \multicolumn{3}{|c|}{$P$} \\
\hline & $\mathrm{CO}$ & PS & $\mathrm{CO}$ & PS & $\mathrm{CO}$ & PS & $\begin{array}{r}\text { Feeding } \\
\text { system (FS) }\end{array}$ & $\begin{array}{r}\text { Anatomical } \\
\text { location }(\mathrm{AL})\end{array}$ & $\mathrm{FS} \times \mathrm{AL}$ \\
\hline $\mathrm{C} 10: 0$ & $1.18 \pm 0.320$ & $0.20 \pm 0.378$ & $1.13 \pm 0.332$ & $0.88 \pm 0.488$ & $1.17 \pm 0.332$ & $1.09 \pm 0.399$ & 0.164 & 0.458 & 0.419 \\
\hline $\mathrm{C} 12: 0$ & $0.11 \pm 0.037$ & $0.19 \pm 0.044$ & $0.16 \pm 0.039$ & $0.34 \pm 0.057$ & $0.17 \pm 0.039$ & $0.31 \pm 0.047$ & 0.001 & 0.038 & 0.550 \\
\hline C14:0 & $2.03 \pm 0.237$ & $2.76 \pm 0.280$ & $2.16 \pm 0.246$ & $2.61 \pm 0.362$ & $2.97 \pm 0.246$ & $2.95 \pm 0.295$ & 0.096 & 0.066 & 0.365 \\
\hline C14:1 & $0.40 \pm 0.109$ & $0.41 \pm 0.130$ & $0.30 \pm 0.114$ & $0.87 \pm 0.167$ & $0.56 \pm 0.114$ & $0.91 \pm 0.137$ & 0.005 & 0.033 & 0.100 \\
\hline C16:0 & $20.48 \pm 0.553$ & $19.95 \pm 0.655$ & $17.73 \pm 0.574$ & $18.78 \pm 0.845$ & $19.80 \pm 0.574$ & $19.36 \pm 0.690$ & 0.960 & 0.017 & 0.438 \\
\hline C16:1 & $1.71 \pm 0.177$ & $2.05 \pm 0.209$ & $2.06 \pm 0.183$ & $1.37 \pm 0.270$ & $2.38 \pm 0.183$ & $1.92 \pm 0.221$ & 0118 & 0.128 & 0.038 \\
\hline $\mathrm{C} 17: 0$ & $1.29 \pm 0.138$ & $1.92 \pm 0.163$ & $1.63 \pm 0.143$ & $2.39 \pm 0.211$ & $1.28 \pm 0.143$ & $2.57 \pm 0.172$ & $<0.001$ & 0.035 & 0.095 \\
\hline $\mathrm{C} 17: 1$ & $0.51 \pm 0.081$ & $0.75 \pm 0.096$ & $0.67 \pm 0.084$ & $0.89 \pm 0.124$ & $0.71 \pm 0.084$ & $0.70 \pm 0.101$ & 0.060 & 0.337 & 0.368 \\
\hline C18:0 & $22.05 \pm 0.905$ & $25.40 \pm 1.071$ & $20.63 \pm 0.939$ & $26.83 \pm 1.383$ & $19.42 \pm 0.939$ & $25.50 \pm 1.129$ & $<0.001$ & 0.387 & 0.302 \\
\hline C18:1n9* & $37.50 \pm 0.802$ & $35.87 \pm 0.949$ & $39.46 \pm 0.832$ & $30.34 \pm 1.225$ & $38.74 \pm 0.832$ & $31.15 \pm 0.998$ & $<0.001$ & 0.092 & $<0.001$ \\
\hline \multicolumn{10}{|l|}{ Sums } \\
\hline SFA & $48.10 \pm 1.028$ & $51.79 \pm 1.216$ & $44.51 \pm 1.066$ & $53.38 \pm 1.570$ & $45.97 \pm 1.066$ & $53.32 \pm 1.282$ & $<0.001$ & 0.719 & 0.095 \\
\hline MUFA & $41.59 \pm 0.855$ & $40.21 \pm 1.011$ & $43.63 \pm 0.887$ & $35.00 \pm 1.306$ & $43.95 \pm 0.887$ & $36.34 \pm 1.066$ & $<0.001$ & 0.308 & 0.001 \\
\hline PUFA & $10.30 \pm 0.550$ & $7.99 \pm 0.651$ & $11.86 \pm 0.571$ & $11.62 \pm 0.840$ & $10.07 \pm 0.571$ & $10.33 \pm 0.686$ & 0.158 & 0.001 & 0.098 \\
\hline DFA & $73.95 \pm 0.713$ & $73.60 \pm 0.843$ & $76.12 \pm 0.740$ & $73.45 \pm 1.089$ & $73.46 \pm 0.740$ & $72.18 \pm 0.889$ & 0.043 & 0.089 & 0.407 \\
\hline \multicolumn{10}{|l|}{ Indexes } \\
\hline$\Delta 9 \mathrm{DS}(\mathrm{C} 16)$ & $7.64 \pm 0.681$ & $9.21 \pm 0.806$ & $10.36 \pm 0.707$ & $6.42 \pm 1.040$ & $10.74 \pm 0.707$ & $8.85 \pm 0.849$ & 0.036 & 0.138 & 0.004 \\
\hline$\Delta 9 \mathrm{DS}(\mathrm{C} 18)$ & $63.00 \pm 1.306$ & $58.57 \pm 1.546$ & $65.75 \pm 1.356$ & $53.16 \pm 1.995$ & $66.72 \pm 1.356$ & $54.98 \pm 1.629$ & $<0.001$ & 0.628 & 0.015 \\
\hline \multicolumn{10}{|l|}{ Ratios } \\
\hline
\end{tabular}

* Sum of the cis and trans isomers. SFA: saturated fatty acids; MUFA: monounsaturated fatty acids; PUFA: polyunsaturated fatty acids;

$\Delta 9 \mathrm{DS}(18)$ : $\Delta 9$-desaturase (C18) index; $\Delta 9 \mathrm{DS}$ (16): $\Delta 9$-desaturase (C16) index.

SC and TF (Nuernberg et al., 2008; Velasco et al., 2001) and intramuscular fats (Cividini et al., 2014; Popova, 2007) from pasture and concentrate lambs. In the present study, no significant difference in the percentage of saturated FAs (SFA) in depot fats was determined. However, the percentage of the SFA in intramuscular fats was higher in PS lambs than in CO lambs $(p<0.001)$.

The percentages of some of the monounsaturated fatty acids (MUFAs) in depot fats, such as C14:1, C16:1, and $\mathrm{C} 17: 1$, was found to be higher in CO lambs than in PS lambs (Table 4). Regarding intramuscular fats, CO lambs were found to have a higher C18:1n9 level than PS lambs (Table 5). These results may be associated with the differences in dietary FA profile and rumen biohydrogenation activity. In a concentrate-based diet, the percentage of the C18:2n6 is quite high compared to that in pasture (Table 1). There is also an observed increase in the synthesis of oleic acid from stearic acid, depending on an increasing level of SterolCoA desaturase ( $\Delta 9$ desaturation) enzyme activity combined with an increased fat deposition (Velasco et al., 2001; Ci- vidini et al., 2014). The $\Delta 9$ desaturation (C18) index, both in depot and intramuscular fats, was found to be higher in CO lambs than in PS lambs ( $p<0.001$; Tables 4 and 5). In similar studies, the C16:1 and/or C18:1 content was high in the concentrate-fed lambs (Cividini et al., 2014; Fisher et al., 2000; Santos-Silva et al., 2002a; Nuernberg et al., 2008), but these results were not found to be significant in other studies (Diaz et al., 2002; Popova, 2007). Moreover, the effect of feeding system on C16:1, C18:1n9 and C18:3n3 varied depending on muscle type, and significant interactions were present for these FAs $(p<0.001)$. The percentages of $\mathrm{C} 18: 1 \mathrm{n} 9$ and $\mathrm{C} 18: 3 \mathrm{n} 3$ were similar in CO and PS lambs for LT, while PS lambs had a lower percentage of C18:1n9 and a higher percentage of $\mathrm{C} 18: 3 \mathrm{n} 3$ than $\mathrm{CO}$ lambs for SM and TB (Table 5). The differences in muscle type in terms of activity and low intramuscular fat deposition in these muscles might cause LT to have different profile for these fatty acids than SM and TB in PS lambs. Hence, Moreno et al. (2006) suggested that low intramuscular fat deposition could alter the FA profile of calves fed on pasture and concentrate. In 
addition to this, Rogowski et al. (2013) reported that increasing $\Delta 9$-desaturase activity of muscle increases triglyceride PUFA content.

The results obtained in this study were similar to those of previous studies (Diaz et al., 2002; Popova, 2007; Rowe et al., 1999), and the percentage of linoleic acid (LA, C18:2n6) was found to be higher in depot and intramuscular fats of $\mathrm{CO}$ lambs than of PS lambs, whereas alpha-linolenic acid (ALA, C18:3n3) levels were higher in the PS lambs except for in LT (Tables 4 and 5). ALA is elongated and desaturated into longer-chain omega-3 FAs, such as $\mathrm{C} 20: 5 \mathrm{n} 3$ (EPA) and C22:6n-3 (DHA), and therefore, the availability of ALA is highly important (Bessa et al., 2015). In general terms, the effect of the feeding system on polyunsaturated FAs (PUFA) in tissues can be associated with the high amount of LA found in concentrate feed and of ALA in pasture (Table 1).

The results of the principal component analysis (PCA) are presented in Fig. 1a. The first component (PC1) explained $52.7 \%$ of the total variation. SC and TF were located on the opposite side of PC1 and were clearly separated from each other. It can be seen that SFA and SC were located on the left side of the PC1 and were associated with each other, whereas PUFA, MUFA, $\Delta 9$ DS 16/18, n6, and TF were located on the right side. The results confirmed the differences between TF and SC and were in agreement with Table 4. The second component (PC2) explained $27.3 \%$ of variability and was characterized by $\mathrm{CO}$, PS, and $\mathrm{n} 3$. CO was located on the opposite side of PS and n3, in PC2, and the relationship between PS and n3 FAs can be clearly seen. This relationship is in agreement with results reported by other researchers (Fisher et al., 2000; Özcan et al., 2015).

The results of PCA analysis in intramuscular FA composition were presented in Fig. 1b. PC1 and PC2 explained 41.7 and $21.1 \%$ of the total variation, respectively. Unlike fat depots, PS was associated with SFA and located on the left side of the first component, opposite to $\mathrm{CO}$, which was related to MUFA and $\triangle 9$ DS $16 / 18$ on the right side of the PC1, in the intramuscular fat. PC2 was characterized by $\mathrm{n} 3$ and PUFA and closer to SM than LT and TB, which were located opposite to PC2.

Some of the total FAs found in depot and intramuscular fats and their ratios, which are used as criteria in healthy nutrition have been shown in Tables 4 and 5. Although there was no significant difference regarding the percentages of the SFA, MUFA, and PUFA in depot fats, both higher SFA $(p<0.001)$ and lower MUFA $(p<0.001)$ levels were found in the intramuscular fats of PS lambs than in that of CO lambs. Similar results were also reported in some previous studies (Diaz et al., 2002; Guler et al., 2011; Özcan et al., 2015; Popova, 2007). The British Department of Health (1994) has recommended the PUFA / SFA ratio to be above 0.45 and the $n 6 / \mathrm{n} 3$ ratio to be below 4.00. Despite a similar PUFA / SFA ratio in depot fats for both groups (Table 4), the ratio was found to be higher in the intramuscular fats of CO lambs than in that of PS lambs $(p<0.01)$ (Ta-
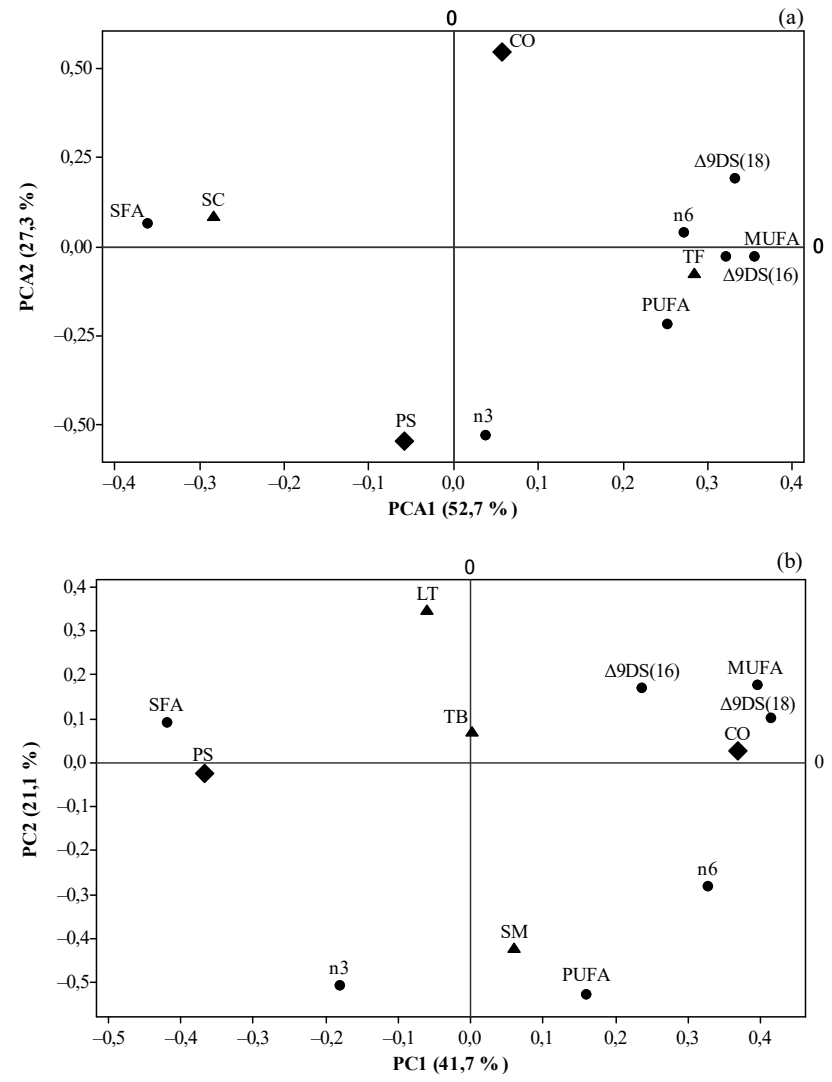

Figure 1. Principal component analysis for some fatty acid groups and indexes (•) of fat depots (a) and intramuscular fat (b) (ム) in different feeding systems $(\diamond)$. CO: concentrate lambs; PS: pasture lambs; SC: subcutaneous; TF: tail fat; LT: longissimus thoracis; SM: semimembranosus; TB: triceps brachii; SFA: saturated fatty acids; MUFA: monounsaturated fatty acids; PUFA: polyunsaturated fatty acids; $\Delta$ 9DS(18): $\Delta 9$-desaturase (C18) index; $\Delta 9 \mathrm{DS}(16)$ : $\Delta 9$ desaturase (C16) index.

ble 5). Moreover, the $\mathrm{n} 6 / \mathrm{n} 3$ ratio in both depot and intramuscular fats was found to be lower in PS lambs than in CO lambs $(p<0.001)$ except for LT.

With the results associated with FA composition in SC and $\mathrm{TF}$, it was determined that the percentage of the SFA was higher in SC, whereas MUFA and PUFA were determined to be higher $(p<0.01)$ in TF (Table 4$)$. It must be noted that the effect of the feeding system on some FAs varies according to individual $\mathrm{SC}$ and $\mathrm{TF}$ and that interactions related to these FAs were found to be significant $(p<0.05)$. Despite the fact that the percentages of the $\mathrm{C} 14: 1, \mathrm{C} 15: 1, \mathrm{C} 16: 1$, and $\mathrm{C} 17: 1$ MUFA as well as $\Delta 9$ desaturation (C16) index in SC and TF of CO lambs showed similarities, the same FAs in the SC of PS lambs were found to be significantly lower when compared to the TF values $(p<0.05)$. In accordance with these results, Gallardo et al. (2014) reported that FA composition, in both $\mathrm{SC}$ and $\mathrm{TF}$ in lambs, varied according to pasture type. The researchers noted that the tissue-specific 
response, depending on the pasture type, may be associated with gene and protein expression or lipogenic enzyme activity (stearoyl-CoA desaturase; SCD). Moreover, TF had a higher PUFA / SFA ratio than SC $(p<0.001)$, and the $\mathrm{n} 6 / \mathrm{n} 3$ ratio of TF was found to be lower than that of $\mathrm{SC}(p<0.05)$. It can be suggested that TF has more beneficial FAs than SC.

Ruminants tend toward storing essential FAs in intramuscular fats instead of depot fats (Wood et al., 2008). Alphalinoleic acid was found to be the most important source of diversity in intramuscular fats $(\mathrm{SM}>\mathrm{TB}>\mathrm{LT} ; p<0.05)$, and SM was the muscle tissue with the highest PUFA / SFA and lowest $\mathrm{n} 6 / \mathrm{n} 3$ ratios (Table 5). Similar results were reported by Coutinho et al. (2014), and SM and TB had higher PUFA / SFA ratios than LT.

\section{Conclusions}

The results of this study showed that the feeding system had an important effect in terms of the many characteristics examined. Compared to the lambs raised on pasture, more fattened carcasses with higher dressing percentages were obtained from the CO lambs. Moreover, it was determined that the feeding system significantly changed the major meat quality characteristics; the PS lambs had meat with a higher $\mathrm{pH}$, darker color, and lower WHC than CO lambs. CO has better index values related with FAs, whereas the percentage of the ALA of PS was found to be higher than CO in all tissues. On the other hand, it must be noted that the effects of the feeding system have varying results based on different types of fat deposits.

Acknowledgements. The present study received support from the Yuzuncu Yil University Scientific Research Project Fund (Project no: 2008-ZF-B070).

Edited by: S. Maak

Reviewed by: two anonymous referees

\section{References}

AOAC: Official Methods of Analysis, Association of Official Analytical Chemists, Maryland, USA, 2000.

Basturk, A., Javidipour, I., and Boyaci, I. H.: Oxidative stability of natural and chemically interesterified cottonseed, palm and soybean oils, J. Food Lipids, 14, 170-188, doi:10.1111/j.17454522.2007.00078.x, 2007.

Bessa, R. J. B., Alves, S. P., and Santos-Silva, J.: Constraints and potentials for the nutritional modulation of the fatty acid composition of ruminant meat, Eur. J. Lipid Sci. Tech., 117, 1325-1344, doi:10.1002/ejlt.201400468, 2015.

Beyis, M. E.: A Study on Botanical Composition and Hay Yield of Pastures in Gevaş District of Van, MSc, Field Crops, Yuzuncu Y1l University, Graduate School of Natural and Applied Science Van, Turkey, 30 pp., 2009.
British Department of Health: Nutritional Aspects of Cardiovascular Disease, HSMO, London, 1994.

Carrasco, S., Panea, B., Ripoll, G., Sanz, A., and Joy, M.: Influence of feeding systems on cortisol levels, fat colour and instrumental meat quality in light lambs, Meat Science, 83, 50-56, doi:10.1016/j.meatsci.2009.03.014, 2009a.

Carrasco, S., Ripoll, G., Sanz, A., Álvarez-Rodríguez, J., Panea, B., Revilla, R., and Joy, M.: Effect of feeding system on growth and carcass characteristics of Churra Tensina light lambs, Livest. Sci., 121, 56-63, doi:10.1016/j.livsci.2008.05.017, 2009b.

Cividini, A., Levart, A., Žgur, S., and Kompan, D.: Fatty acid composition of lamb meat from the autochthonous Jezersko-Solčava breed reared in different production systems, Meat Science, 97, 480-485, doi:10.1016/j.meatsci.2013.12.012, 2014.

Colomer-Rocher, F., Morand-Fehr, P., and Kirton, A. H.: Standard methods and procedures for goat carcass evaluation, jointing and tissue separation, Livest. Prod. Sci., 17, 149-159, doi:10.1016/0301-6226(87)90060-1, 1987.

Coutinho, M. A. D. S., Morais, M. D. G., Coelho, R. G., Alves, F. V., Fernandes, H. J., Ítavo, C. C. B. F., Comparin, M. A. S., and Ribeiro, C. B.: Lipid profile and cholesterol in meat cuts of ewe lambs fed different levels of concentrate, Semina: Ciências Agrárias, 35, 3355-3366, doi:10.5433/16790359.2014v35n6p3355, 2014.

Diaz, M. T., Velasco, S., Cañeque, V., Lauzurica, S., Ruiz de Huidobro, F., Pérez, C., González, J., and Manzanares, C.: Use of concentrate or pasture for fattening lambs and its effect on carcass and meat quality, Small Ruminant Res., 43, 257-268, doi:10.1016/S0921-4488(02)00016-0, 2002.

Duckett, S. K., Neel, J. P., Lewis, R. M., Fontenot, J. P., and Clapham, W. M.: Effects of forage species or concentrate finishing on animal performance, carcass and meat quality, J. Animal Sci., 91, 1454-1467, doi:10.2527/jas.2012-5914, 2013.

EEC: No. $2568 / 91$ of 11 July 1991 on the characteristics of olive oil and olive-residue oil and on the relevant methods of analysis, Official Journal of the European Communities, L248, 1-82, 1991.

Fisher, A. V., Enser, M., Richardson, R. I., Wood, J. D., Nute, G. R., Kurt, E., Sinclair, L. A., and Wilkinson, R. G.: Fatty acid composition and eating quality of lamb types derived from four diverse breed $\times$ production systems, Meat Science, 55, 141-147, doi:10.1016/S0309-1740(99)00136-9, 2000.

Folch, J., Lees, M., and Sloane Stanley, G. H.: A simple method for the isolation and purification of total lipides from animal tissues, J. Biol. Chem., 226, 497-509, 1957.

Gallardo, M. A., Dannenberger, D., Rivero, J., Pulido, R., and Nuernberg, K.: Fatty acid profile of plasma, muscle and adipose tissues in Chilota lambs grazing on two different low quality pasture types in Chiloé Archipelago (Chile), Anim. Sci. J., 85, 935941, doi:10.1111/asj.12227, 2014.

Guler, G. O., Aktumsek, A., and Karabacak, A.: Effect of Feeding Regime on Fatty Acid Composition of Longissimus dorsi Muscle and Subcutaneous Adipose Tissue of Akkaraman Lambs, Kafkas Universitesi Veteriner Fakultesi Dergisi, 17, 885-892, doi:10.9775/kvfd.2011.4495, 2011.

Huerta-Leidenz, N. O., Cross, H. R., Lunt, D. K., Pelton, L. S., Savell, J. W., and Smith, S. B.: Growth, carcass traits, and fatty acid profiles of adipose tissues from steers fed whole cottonseed, J. Animal Sci., 69, 3665-3672, doi:1991.6993665x, 1991. 
Immonen, K., Ruusunen, M., Hissa, K., and Puolanne, E.: Bovine muscle glycogen concentration in relation to finishing diet, slaughter and ultimate $\mathrm{pH}$, Meat Science, 55, 25-31, doi:10.1016/S0309-1740(99)00121-7, 2000.

Jenkins, T. C., Wallace, R. J., Moate, P. J., and Mosley, E. E.: Boardinvited review: Recent advances in biohydrogenation of unsaturated fatty acids within the rumen microbial ecosystem, J. Animal Sci., 86, 397-412, doi:10.2527/jas.2007-0588, 2008.

Juárez, M., Horcada, A., Alcalde, M. J., Valera, M., Mullen, A. M., and Molina, A.: Estimation of factors influencing fatty acid profiles in light lambs, Meat Science, 79, 203-210, doi:10.1016/j.meatsci.2007.08.014, 2008.

Karaca, S.: Fattenıng performance, slaughter and carcass characteristics, meat quality and fatty acid composition of Karakaş lambs and Hair goat kids on intensive and extensive conditions, $\mathrm{PhD}$, Animal Science, Yuzuncu Y1l University, Graduate School of Natural and Applied Science Van, Turkey, 145 pp., 2010.

Karaca, S. and Kor, A.: Effect of feeding system on meat quality and fatty acid profile of lambs slaughtered at the same age or live weight, VII: Balkan Conference on Animal Science, IlidzaSarajevo, Bosnia and Herzegovina, 3-6 June, 2015.

Minchin, W., Buckley, F., Kenny, D. A., Monahan, F. J., Shalloo, L., and O'Donovan, M.: Effect of grass silage and concentrate based finishing strategies on cull dairy cow performance, carcass and meat quality characteristics, Meat Science, 81, 93-101, doi:10.1016/j.meatsci.2008.07.001, 2009.

Moreno, T., Franco, D., Bispo, E., Perez, N., and Monserrat, L.: Effect of the finishing diets on beef nutritional composition of six commercial muscles, edited by: Declan, T., Rachel, P., Briege, B., and Joseph, K., 52th International Congress of Meat Science and Technology, Wageningen Academic Publishers, the Netherlands, 119-121, 2006.

Moron-Fuenmayor, O. E. and Clavero, T.: The effect of feeding system on carcass characteristics, non-carcass components and retail cut percentages of lambs, Small Ruminant Res., 34, 57-64, doi:10.1016/S0921-4488(99)00038-3, 1999.

Nuernberg, K., Fischer, A., Nuernberg, G., Ender, K., and Dannenberger, D.: Meat quality and fatty acid composition of lipids in muscle and fatty tissue of Skudde lambs fed grass versus concentrate, Small Ruminant Res., 74, 279-283, doi:10.1016/j.smallrumres.2007.07.009, 2008.

Özcan, M., Demirel, G., Yakan, A., Ekiz, B., Tölü, C., and Savaş, T.: Genotype, production system and sex effects on fatty acid composition of meat from goat kids, Anim. Sci. J., 86, 200-206, doi:10.1111/asj.12273, 2015.

Papi, N., Mostafa-Tehrani, A., Amanlou, H., and Memarian, M.: Effects of dietary forage-to-concentrate ratios on performance and carcass characteristics of growing fat-tailed lambs, Anim. Feed Sci. Tech., 163, 93-98, doi:10.1016/j.anifeedsci.2010.10.010, 2011.

Popova, T.: Effect of the rearing system on the fatty acid composition and oxidative stability of the M. longissimus lumborum and M. semimembranosus in lambs, Small Ruminant Res., 71, 150157, doi:10.1016/j.smallrumres.2006.06.001, 2007.

Priolo, A., Micol, D., and Agabriel, J.: Effects of grass feeding systems on ruminant meat colour and flavour. A review, Animal Res., 50, 185-200, doi:10.1051/animres:2001125, 2001.
Priolo, A., Micol, D., Agabriel, J., Prache, S., and Dransfield, E.: Effect of grass or concentrate feeding systems on lamb carcass and meat quality, Meat Science, 62, 179-185, doi:10.1016/S03091740(01)00244-3, 2002.

Ripoll, G., Joy, M., Muñoz, F., and Albertí, P.: Meat and fat colour as a tool to trace grass-feeding systems in light lamb production, Meat Science, 80, 239-248, doi:10.1016/j.meatsci.2007.11.025, 2008.

Rogowski, M. P., Flowers, M. T., Stamatikos, A. D., Ntambi, J. M., and Paton, C. M.: SCD1 activity in muscle increases triglyceride PUFA content, exercise capacity, and PPAR $\delta$ expression in mice, J. Lipid Res., 54, 2636-2646, doi:10.1194/jlr.M035865, 2013.

Rowe, A., Macedo, F. A. F., Visentainer, J. V., Souza, N. E., and Matsushita, M.: Muscle composition and fatty acid profile in lambs fattened in drylot or pasture, Meat Science, 51, 283-288, doi:10.1016/S0309-1740(98)00063-1, 1999.

Santos-Silva, J., Bessa, R. J. B., and Santos-Silva, F.: Effect of genotype, feeding system and slaughter weight on the quality of light lambs: 2. Fatty acid composition of meat, Livest. Prod. Sci., 77, 187-194, doi:10.1016/S0301-6226(02)00059-3, 2002a.

Santos-Silva, J., Mendes, I. A., and Bessa, R. J. B.: The effect of genotype, feeding system and slaughter weight on the quality of light lambs: 1 . Growth, carcass composition and meat quality, Livest. Prod. Sci., 76, 17-25, doi:10.1016/S03016226(01)00334-7, 2002b.

Sanudo, C., Campo, M., Olleta, J. L., Joy, M., and Delfa, R.: Methodologies to Evaluate Meat Quality in Small Ruminants, in: Evaluation of Carcass and Meat Quality in Cattle and Sheep edited by: Sanudo, C., Gigli, S., and Gabina, D., Wageningen Academic, the Netherlands, 81-105, 2007.

Van Soest, P. J. and Robertson, J. B.: Systems of analyses for evaluation of fibrous feed, in: Proc. Int. Workshop on Standardization of Analytical Methodology for Feeds, edited by: Pigden, W. J., Balch, C. C., and Graham, M., Ottowa, Canada, 49-60, 1979.

Velasco, S., Cañeque, V., Pérez, C., Lauzurica, S., Diaz, M. T., Huidobro, F., Manzanares, C., and González, J.: Fatty acid composition of adipose depots of suckling lambs raised under different production systems, Meat Science, 59, 325-333, doi:10.1016/S0309-1740(01)00135-8, 2001.

Wierbicki, E. and Deatherage, F. E.: Water Content of Meats, Determination of Water-Holding Capacity of Fresh Meats, J. Agr. Food Chem., 6, 387-392, doi:10.1021/jf60087a011, 1958.

Wood, J. D., Enser, M., Fisher, A. V., Nute, G. R., Sheard, P. R., Richardson, R. I., Hughes, S. I., and Whittington, F. M.: Fat deposition, fatty acid composition and meat quality: A review, Meat science, 78, 343-358, doi:10.1016/j.meatsci.2007.07.019, 2008.

Zervas, G. and Tsiplakou, E.: The effect of feeding systems on the characteristics of products from small ruminants, Small Ruminant Res., 101, 140-149, doi:10.1016/j.smallrumres.2011.09.034, 2011.

Zock, P. L., de Vries, J. H., and Katan, M. B.: Impact of myristic acid versus palmitic acid on serum lipid and lipoprotein levels in healthy women and men, Arterioscl. Throm. Vas., 14, 567-575, doi:10.1161/01.atv.14.4.567, 1994 